\title{
Transformice, um game online para o ensino de conceitos de Matemática no Ensino Fundamental - Desafios e Oportunidades
}

\author{
Geiseane Lacerda Rubi - UNIRITTER, PGIE - UFRGS, Brasil \\ geiserubi@gmail.com \\ Lúcia Maria Martins Giraffa - PUCRS, Brasil \\ giraffa@pucrs.br
}

Resumo: Este artigo apresenta uma proposta metodológica utilizando o game online Transformice para o ensino de conceitos de Matemática. Para tanto, desenvolveu-se uma sequência didática abordando dois eixos de ensino: "Espaço e Forma" e "Grandezas e Medidas". Em cada eixo foram desenvolvidas atividades de modo a explorar o jogo e as relações entre os ângulos, arcos, Teorema de Pitágoras, entre outros conceitos estudados no Ensino Fundamental. A pesquisa de cunho qualitativo, utilizou para coleta dos dados questionários, entrevista, diário de aula e análise documental (registro das atividades desenvolvidas durante o experimento) os quais foram analisados sob a Análise Textual Discursiva de Moraes e Galiazzi. Os resultados da investigação demonstraram que as expectativas relacionadas ao uso de um game online, devidamente contextualizado por uma proposta pedagógica, auxilia os alunos a estudar conceitos de Matemática causando um duplo e benéfico efeito: entender a aplicação do conteúdo estudado na solução dos problemas do cotidiano, além de auxiliá-los a melhorar seu desempenho como jogadores.

Palavras-chave: ensino de matemática, educação apoiada em tecnologias, jogos online, metodologias de ensino.

Abstract: This paper presents a methodology using the online game Transformice for teaching mathematics concepts. Thus, a didactic sequence addressing two teaching axes developed: "Space and Form" and "Quantities and Measurements". In each axis were developed activities to explore the game and the relationship between the angles, arches, Pythagorean theorem, among other concepts studied in elementary school. The qualitative research was used to collect data from questionnaires, interviews, daily lecture and documentary analysis (log of the activities performed during the experiment) which were analyzed from the Text Analysis of Discourse Moraes and Galiazzi. Research results have shown that expectations related to the use of an online game, properly contextualized by a pedagogical proposal, helps students to study concepts of Mathematics causing a double and beneficial effect: to understand the application of the study content in solving real-world problems as well as help them to improve their performance as players.

Keywords: math teaching, education supported by technologies, online games, teaching methodologies.

\section{Introdução}

É comum reclamações gerais quanto a falta de interesse dos alunos e dificuldades em aprender Matemática, além da resolução mecânica de exercícios. Nesse âmbito, os games podem tornar-se grandes aliados ao "resgate" ao aluno e sua motivação para aprender Matemática, apesar de desafiante para o docente.

Porém, a abordagem tradicional ainda predomina nas aulas de Matemática, com aulas expositivas e exercícios de fixação que obedecem a um modelo previamente apresentado pelo professor. $\mathrm{O}$ aluno continua sendo um ser passivo e o professor o 
detentor do conhecimento (BEHRENS, 2005), mas essa realidade escolar não condiz com o perfil de discente presente na sociedade. Tendo em vista que para a população atual, uma sociedade da cibercultura, que é imersa no mundo virtual e usuária da Internet e seus serviços, os games online ganham força e adeptos entre os jovens.

Os games são uma boa estratégia de ensino, porém os de caráter educacional nem sempre são interessantes, envolventes, divertidos e desafiadores como aqueles que nossos estudantes costumam jogar. Ao observar os alunos nos intervalos das aulas, os relatos de colegas, familiares e reportagens em mídia impressa e digital percebe-se que os games online (jogados na Internet) estão ganhando um espaço significativo como alternativa de lazer e socialização dos jovens.

Comecei, então, a questionar o que há de tão interessante, instigador e motivacional para eles dedicarem tantas horas do seu dia a tal atividade? E a resposta, obtida de forma empírica por meio de diálogos com os alunos, é que os jogos são desafiadores, dinâmicos, possuem interfaces de alta qualidade gráfica, permitem o estabelecimento de comunidades e parcerias para definição de estratégias conjuntas. Ou seja, o ambiente criado no ciberespaço onde os jogos online acontecem é atrativo, envolvente e interessante para os nossos estudantes que possuem acesso a este tipo de recursos.

Unindo estes questionamentos e reflexões sobre os jogos à tradicional inquietação dos alunos sobre a aplicação de conteúdos de Matemática, ou seja, os questionamentos dos alunos: "onde eu vou usar isto professora?" e a aversão dos mesmos pela disciplina de Matemática escolheu-se os Jogos na Educação Matemática como área de investigação.

O uso dos jogos na educação já vem sendo sugeridos por Mattar (2010) e Prensky $(2001,2010)$ quando afirmam que os alunos de hoje em dia, compõem uma nova geração, aprendem diferente, pois são uma geração digital, de interação, ou ainda, conforme denomina Prensky (2001) Nativo Digital ou Homo Zappiens de acordo com Veen e Vrakking (2009). Sendo assim os jogos são um importante, interessante e envolvente meio para o ensino de diversas disciplinas curriculares, neste caso, para o ensino de Matemática.

No Brasil, esta medida já vem sendo adotada com sucesso, desde 2012 em três escolas de São Paulo. Professores da disciplina de Educação Física adotam o ensino de modalidades esportivas por meio de jogos digitais. Além de uma abordagem divertida de conteúdos curriculares, os jogos enriquecem as aulas, pois os estudantes tem a possibilidade de explorar e conhecer melhor modalidades esportivas que não são comuns no país em função da estrutura física necessária, como por exemplo, o atletismo.

Considerando o problema e o contexto mencionado e a partir das motivações apresentadas emergiu a questão de pesquisa que norteou este trabalho: "Quais as competências e habilidades matemáticas que os alunos podem desenvolver ao jogarem games online?"

Para aporte teórico utilizou-se a perspectiva construtivista, uma vez que busca valorizar o saber do estudante e o envolve no processo de construção do seu conhecimento, valorizando seu conhecimento prévio e utiliza-se de "pontes cognitivas" entre o saber esperado e estado corrente do saberes do aluno para o entendimento de conceitos de Matemática. Buscou-se com esta proposta metodológica desenvolver interativamente o conhecimento, motivando o aluno à reflexão e interação.

\section{Processos e Métodos}


Esta pesquisa foi realizada em três etapas amplas que são compostas por subetapas. Assim, na primeira etapa investigaram-se, a partir de questionários, quais os games online são utilizados por 75 alunos do Ensino Fundamental de uma escola privada do município de Porto Alegre/RS, a fim de selecionar um game. O game selecionado foi o elemento apoiador do estudo de conteúdos relacionados à Matemática previstos na grade curricular do ano selecionado. A escolha pelo $8^{\circ}$ ano do Ensino Fundamental deu-se em função da análise do jogo e sua dinâmica, interfaces e estrutura. Uma vez que as características do jogo foram definidoras da associação que se fez com o estudo de Matemática.

A segunda etapa, após a seleção do game online Transformice, identificou-se que habilidades e competências matemáticas os alunos utilizam para obter sucesso no jogo, ou seja, para passar de fase, ganhar vidas e vencer o jogo. Também foi verificado com os alunos, a partir de entrevistas semi-estruturadas, se eles reconhecem a Matemática aplicada no jogo. E, finalmente determinaram-se quais conteúdos curriculares de Matemática foram abordados a partir do jogo selecionado.

Posteriormente, para a concretização dos objetivos, foi elaborada uma sequência didática que utilizou o jogo online como ferramenta tecnológica para o ensino dos conteúdos curriculares previamente determinados pelo plano de ensino anual da escola. $\mathrm{O}$ experimento, ou seja, as intervenções realizadas utilizando o jogo selecionado realizaram-se durante 22 horas/aula e uma turma (21 alunos) de $8^{\circ}$ ano do Ensino Fundamental. Neste sentido, outros instrumentos para coleta de dados constituem a análise instrumental (questionários, atividades elaboradas pelos alunos, avaliações), observação participante no experimento que se realizou, bem como o diário de campo, ou ainda, diário de aula.

O diário de aula (DA) é um documento cujo professor/pesquisador anota suas observações, suas percepções e perspectivas, descreve sujeitos, cenários e situações conforme ocorrem com o objetivo de se aprofundar na pesquisa. Zabalza (2004, p. 14) assegura que não é obrigatório ser uma atividade diária, porém salienta a importância da "continuidade na coleta e na redação das narrações", pois quando imersa no contexto de pesquisa e sob perspectiva qualitativa o conjunto é essencial a análise posterior. Ainda Zabalza (2004, p. 16) reitera que "O bom de um diário, o que se torna um importante documento para o desenvolvimento pessoal, é que nele se possa contrastar tanto o objetivo-descritivo como o reflexivo-pessoal.", por isso o DA é um registro, que sob o ponto de vista metodológico, garante a veracidade da pesquisa realizada, mas, além disto, expressa intenções e análises iniciais da perspectiva do professor enquanto ser integrante na pesquisa permitindo a inter-relação entre a realidade e a intervenção.

Neste sentido, durante o experimento, foi realizada a análise e observação participante da interação e experiência didático-pedagógica. As intervenções foram registradas através no DA, onde foram anotadas falas dos alunos que participaram do experimento, bem como, comentários e reflexões a fim de retratar a investigação realizada.

Ao final das intervenções, os alunos responderam ao questionário online criado no Google Form, com o objetivo de analisar e refletir sobre o uso do jogo comercial online selecionado nas aulas de Matemática.

Por fim, para a análise qualitativa dos dados coletados utilizou-se a metodologia de análise textual discursiva de Roque Moraes e Maria do Carmo Galiazzi (2011). Esta metodologia visa a compreensão desses dados, por meio de um processo autoorganizado que tem por objetivo compreender com um novo e mais aprofundado "olhar" dos dados coletados.

Por esse ângulo, as categorias "a priori” elencadas nesta pesquisa são: 
1. Motivação: Acredita-se que por meio da interação entre o jogo selecionado nas aulas de Matemática os estudantes sintam-se motivados para estudar aumentando o interesse nos estudos e desmistificando a disciplina.

2. Associação: O uso do jogo comercial online como ferramenta de ensino de Matemática proporciona a reflexão para compreender e associar a teoria do conteúdo curricular e a prática no jogo. Ou seja, percebe a Matemática aplicada diretamente ou intuitivamente nos jogos, isto é, na sua vida.

3. Compreensão: O jogo é uma ponte cognitiva e, ao mesmo tempo, um conhecimento prévio que o aluno possui, logo ao utilizá-lo como meio para exercitar e relacionar conceitos de Matemática torna-se um mediador e um grande aliado na compreensão de conceitos e conteúdos curriculares.

4. Proatividade e Autonomia: Ao interagir com o jogo mediante reflexões entre conteúdo e aplicação acredita-se no desenvolvimento da proatividade e autonomia, tendo em vista que com uma perspectiva diferenciada de ensino os estudantes sintam-se confiantes, neste sentido tomam iniciativas, arriscam-se e, por consequência, tornam-se autônomos e proativos, pois pensam, analisar e agem por antecipação, ou seja, desenvolvem a toma de decisão.

5. Interação: Com a perspectiva dinâmica e envolvente que o jogo proporciona acredita-se que aumente a interação entre os alunos, bem como o respeito e as "trocas" entre eles.

6. Colaboração: Diante a interação proporcionado com o jogo, como consequência disso, almeja-se que se desenvolva a colaboração pensando da perspectiva de reflexões sob as estratégias e relações entre jogo e conteúdo.

\section{Transformice no ensino de conceitos de Matemática}

Na Figura 1 é apresentada a interface do game Transformice, nele o jogador é um ratinho e tem o objetivo de buscar um queijo (1) e levá-lo até a toca (2). O jogador tem, no máximo, 2 minutos para realizar esta tarefa, pois é o tempo (3) de cada rodada em um determinado mapa. Em um mesmo mapa há diversos jogadores juntos, são 20 ou mais ratinhos interagindo no jogo. A fim de se auto identificar no jogo, o apelido do jogador aparece em amarelo e dos outros ratinhos em branco. Em cada mapa há um líder, esse líder é chamado de Shaman (4) e seu apelido aparece em azul para que todos os jogadores possam identificá-lo, o Shaman é o jogador com maior pontuação na sala e tem o objetivo de ajudar os outros ratinhos. Para isto dispõe de objetos (5) que servem de apoio, dependendo da estratégia que o shaman estabelecer. Além disto, ele orienta os ratinhos que solicitam ajuda e informa dicas para que todos os jogadores consigam pegar o queijo e levá-lo até a toca. O Shaman tem por objetivo salvar o máximo de ratinhos possíveis, para isto deve ajudar todos com os recursos disponíveis no jogo. Já os outros jogadores têm por objetivo ser first, ou seja, ser o primeiro rato a pegar o queijo e levá-lo na toca. Caso contrário, o objetivo mínimo é buscar o queijo e levá-lo para toca independente de colocação.

No mapa há disponível um chat (6), este serve como um meio para a comunicação entre os jogadores, além disto, é um dos recursos disponíveis para a colaboração entre os competidores. Este é outro diferencial do jogo, pois a colaboração e o auxílio entre os competidores são essenciais, tendo em vista que, se porventura, há apenas um ratinho que não consegue levar o queijo até a toca, todos os outros jogadores que já conseguiram ou morreram precisam aguardar o sucesso do ratinho, ou ainda, esgotar o tempo. Assim, todos os jogadores por meio do chat colaboram ajudando uns aos outros. 
Apesar de ser um game colaborativo e todos os jogadores pontuarem, seja como ratinho ou como shaman, e independente do objetivo concretizado, ou seja, independente de conseguir buscar o queijo e levá-lo até a toca, ou de ser o primeiro a levar o queijo, ou ainda, de conseguir salvar todos os ratinhos, os jogadores ganham, no mínimo, um ponto. Embora todos pontuem, o Transformice é considerado um jogo de competição, visto que apresenta um ranking mundial, além disto, apresenta a análise gráfica e porcentagem do desempenho do jogador em relação ao desempenho do primeiro do ranking. Assim, o jogador pode analisar e planejar seu empenho para melhor o desempenho. Atualmente há 16.571.341 jogadores no ranking e este é atualizado diariamente. O primeiro lugar do ranking cria eventos e dá nome a títulos que são disputados por todos os jogadores. Um exemplo de evento seria jogar durante duas semanas mapas temáticos (natal, dia dos namorados, ...) para ganhar acessórios e customizar os ratinhos.

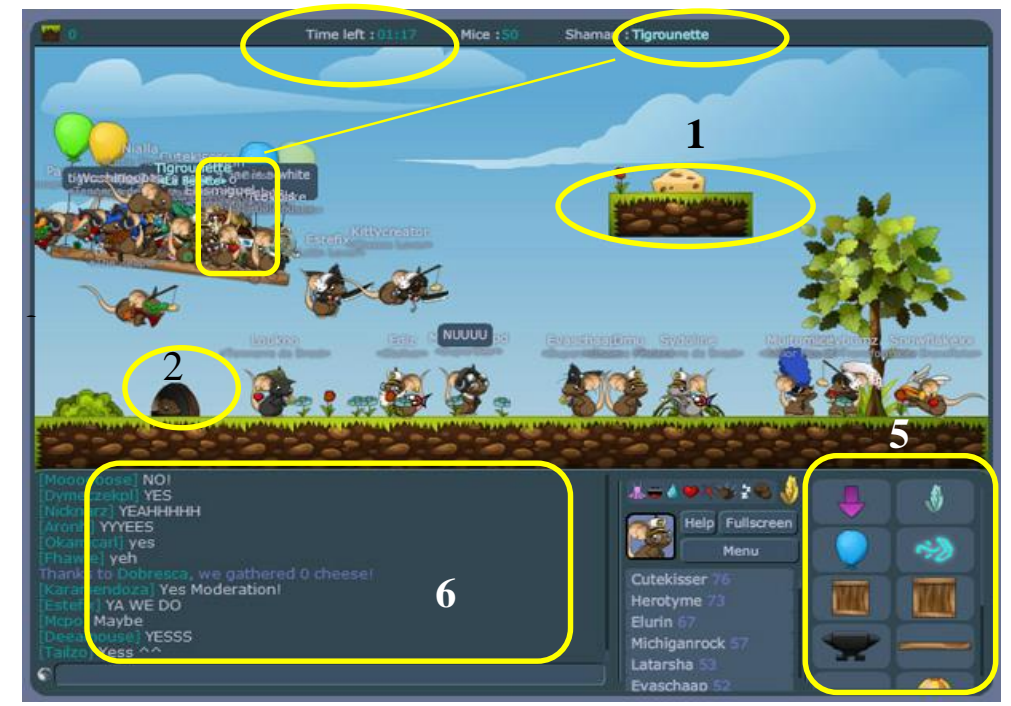

Figura 1: Transformice - game comercial online selecionado pelos alunos. Fonte: http://www.transformice.com/.

A proposta do ensino de conceitos de Matemática com o jogo Transformice foi desenvolvida sob a abrangência de dois eixos de estudo, Espaço e Forma e Grandezas e Medicas. O primeiro abordou o estudo dos ângulos - tipos e suas relações, figuras geométricas, tipos de retas, concomitantemente com o estudo do conteúdo conforme abordagem do livro didático adotado pela instituição de ensino. Já o segundo eixo versa sobre o estudo do Teorema de Pitágoras com seus elementos (catetos e hipotenusa).

A sequência didática visou utilizar o Transformice como um recurso na aprendizagem de conceitos de Matemática relacionando o jogo, que em princípio, não apresenta nada de Matemática com os conteúdos estudados. As atividades desenvolvidas com os alunos tiveram o objetivo de aplicar o conteúdo estudado, seja de maneira interativa e intuitiva, seja de maneira formal, além disto, diversas atividades tiveram o objetivo de refletir sobre as possibilidades de aplicação direta ou indireta do conteúdo. Algumas atividades foram desenvolvidas em aula e outras como atividade extraclasse.

O experimento inicia com o eixo de Espaço e Forma, antes de qualquer interação foi solicitado que os alunos respondessem, por email, quais eram suas expectativas para o estudo com o jogo, além disto, se percebem alguma relação entre o jogo e a disciplina de Matemática. Após, irão jogar segundo a percepção de análise e reflexão do jogo e seus recursos/processos. Passado isto, o diálogo para a troca de reflexões é necessário buscando identificar os conhecimentos prévios dos alunos quanto às figuras geométricas 
que reconhecem, tipos de retas, bem como os tipos de ângulos para, então, iniciar o estudo de ângulos e arcos verificando como identificar, medir, construir e calcular. Logo, exercitar é necessário, para isto, aplicar o conhecimento estudado de arcos e formas geométricas no Transformice na construção de mapas. Do mais, quando a proposta é de construir a Estrela de Davi (exercício do livro didático) junto ao mapa torna-se uma maneira intuitiva de conhecer ângulos suplementares, tendo em vista que para a construção é preciso informar o suplemento do ângulo descrito. Por fim, compartilham seus mapas apresentando os conhecimentos aplicados na construção.

Outro conceito reforçado com o auxílio do Transformice, além de ser outra aplicação de arcos, é a construção de gráficos de setores. Para isto, os alunos verificaram seus rankings com o objetivo de analisar probabilisticamente o próprio desempenho com os colegas, de modo a progredir no jogo.

Por fim, relacionado ao Eixo Espaço e Forma, os alunos realizam atividades que aplicam e calculam diretamente ângulos suplementares e complementares, bem como ângulos opostos pelo vértice. Assim, o objetivo de internalizar uma estimativa de ângulos para a construção quando Shaman e nos mapas de modo a aplicar estes conceitos estudados em sala de aula auxiliando-os no melhor desempenho.

Já no eixo Grandezas e Medidas, o conteúdo abordado para ser ensinado com o Transformice é o Teorema de Pitágoras. Por meio de atividades práticas com quebracabeças busca-se a compreensão intuitiva do teorema, bem como a identificação de seus elementos. Refletir sobre as possibilidades que o teorema proporciona enquanto aplicação é essencial para que os alunos possam relacionar o conteúdo com o jogo. Assim, identificar o Teorema de Pitágoras no Transformice refletindo sobre como este teorema pode auxiliar no desempenho no jogo (Shaman auxiliar os ratos a pegar o queijo). Ao exercitar o teorema com exercícios formais e concomitantemente com o jogo proporciona aos estudantes a possibilidade de melhor o desempenho no Transformice, tendo em vista que aprimora a estimativa de distância e abre seus horizontes na criação de estratégias quando Shaman, pensando em auxiliar o maior número de ratos, no menor tempo possível.

Neste sentido, o ensino por meio de jogos perpassa pela dinâmica interativa de rede de significados fazendo com que os alunos possam relacionar o jogo como uma aplicação do conteúdo estudado, pois segundo Moreira (1999, p. 1), "a estrutura cognitiva de cada aluno é dinâmica na medida em que o processo interativo levá-lo a ressignificar continuamente seus conhecimentos". Assim, o ato do aluno refletir sobre possibilidades que se criam no momento em que o mesmo relaciona o conteúdo com o jogo são essenciais para a sociedade atual da cibercultura que vai à escola para aprender a solucionar problemas de sua vida cotidiana.

Além disto, Sánchez Huete e Fernández Bravo (2009, p.71) reiteram "Trata-se de um processo no qual se combinam diferentes elementos que o aluno possui, como os pré-conceitos, as regras, as habilidades... Exige uma grande dose de reflexão [...] É importante que essa aprendizagem sustente-se na realidade". Logo, a partir da interação com o conhecido (jogo), objeto esse que antes era apenas uma diversão passa a ser um exercício de Matemática. É necessário pensar sobre suas tomadas de decisões percebendo a aplicação do conteúdo estudado.

\section{Resultados e Discussões}

O experimento foi realizado com uma turma do $8^{\circ}$ ano do Ensino Fundamental (21 alunos) através da aplicação da proposta de ensino de conceitos de Matemática com o game online Transformice. Apresentam-se atividades que foram fundamentais no trabalho desenvolvido. As primeiras impressões dos alunos, expressas no questionário, 
não surpreenderam a expectativa da pesquisadora, pois salientaram a motivação em trabalhar com o jogo nas aulas de Matemática, além da ansiedade e curiosidade que tinham em compreender como seriam as aulas com os jogos. Além disto, expressaram quais conteúdos, na opinião dos estudantes, poderiam ser abordados com o jogo. $\mathrm{O}$ Aluno 1 afirma que "Bom, no transformice eu acho que aprenderei é as medidas certas para pular e não morrer, formas geométricas e calcula o tempo e ângulos para conseguir (caso eu seja o shamãn) salvar os ratinhos. [...] Eu percebo é as formas geométricas que tem nos mapas.", já o Aluno 5 expressa que no jogo visualiza a possibilidade de estudar e aplicar os "ângulos, formas (Circulo, Retângulo, Quadrado, entre outros ), velocidade e aderência" e, finalmente, o Aluno 21 salienta que "O jogo transformice tem muita Matemática envolvida como as formas, as retas ângulos e as trajetórias."

Entretanto, o registro no diário de aula refletiram, na mesma intensidade que os alunos se mostraram, a ansiedade e insegurança frente esta desafiadora proposta. Questionamentos como "Será que vai dar certo? Os alunos vão gostar? Vão conseguir relacionar com o conteúdo? A escola vai seguir firma me apoiando? E os pais, vão vir cobrar e reclamar que não estão tendo aula?! Será que os alunos não vão ir para o laboratório e querer apenas jogar perdendo o "controle"?". A insegurança e, ao mesmo tempo, motivação de ambas as partes ficou claro desde o início da proposta refletindo no comprometimento os envolvido, neste sentido, Veen e Vrakking (2009, p. 24) corrobora que "Lidar com o tempo e com a incerteza, com a mudança e o desenvolvimento está se tornando a atividade mais valorizada: essa atividade é a aprendizagem.". Neste ponto refere-se a aprendizagem dos alunos, pois saem da zona de conforto, uma vez que se deparam com jogo conhecido e, por muitos, dominado, porém é necessário um novo olhar, ou seja, novas perspectivas, reflexões e observações.

$\mathrm{Na}$ intenção deste novo "olhar" frente ao jogo, os alunos, no laboratório de informática jogaram livremente e, após, compartilharam o que de Matemática o jogo aborda. Assim, a partir de alguns mapas os alunos identificaram a Matemática presente, algumas das opiniões iniciais se repetiram como formas geométricas e ângulos, entretanto novas ideias surgiram neste diálogo pensando na Matemática aplicada enquanto se joga e não apenas no cenário, se confirmou então a sugestão do Aluno 5 como velocidade e aderência, além disto, sugeriram a distância, tempo, raciocínio lógico para a tomada de decisão e criação de estratégias a serem aplicadas no jogo.

Outro objetivo foi utilizar o recurso que o próprio jogo apresenta, visando melhorar o desempenho dos estudantes no jogo, utilizaram-se do ranking dos jogadores do Transformice analisando e comparando graficamente seus desempenhos tendo em vista a melhoria. Neste sentido, os alunos fizeram gráficos de setores (Figura 2) para expressar essa comparação, após, em grupos discutiram possibilidades e estratégias para melhorar o desempenho e ainda no que a Matemática poderia auxiliar para melhorar esse desempenho. Assim, ao realizar esta atividade os alunos aplicaram conceitos de gráficos, cálculo de porcentagem, além de arcos visando uma maneira de exercitar esses conteúdos, tendo em vista que esses conceitos foram estudados pelos alunos durante o trimestre vigente.

A proposta da construção dos mapas (Figura 3) no Transformice culminou o estudo do eixo de Espaço e Forma aplicando os conceitos estudados de figuras geométricas (polígonos e corpos redondos) e arcos, além disto, de maneira intuitiva introduziu o conceito de ângulo interno, externo e, principalmente, suplemento de um ângulo, pois ao construírem no mapa a Estrela de Davi foi necessário informar o ângulo interno e o ângulo externo de modo a construir o triângulo, logo informar o suplemento do ângulo interno. Posterior a construção, os alunos apresentaram seus mapas compartilhando o trabalho e exemplificando a Matemática aplicada no mapa. O Aluno 
19, no momento da apresentação, informou da dificuldade que sentiu para a construção do mapa, pois, segundo suas palavras, "Sora, eu não conseguia, não conseguia... fui chutando vários ângulos para ver se dava certo, mas nunca dava. Ai, depois de um tempão me dei conta que era o que faltava para chegar em $180^{\circ}$, ai deu certo para todos os outros lados.", corroborando com esta ideia, o Aluno 8 afirmou "É muito fácil só tem que botar o ângulo que ta faltando... faltando não, o que vai chegar até, porque só tem como fazer as retas iguais e retas...(risos)... é aquelas... paralelas, ai só vai virá se a gente coloca o ângulo, mas é bem fácil sora!”.

Finalizadas as apresentações dos mapas, os conceitos de ângulos internos e externos, ângulos suplementares e complementares, bem como ângulos adjacentes e opostos pelo vértice foram formalizados.
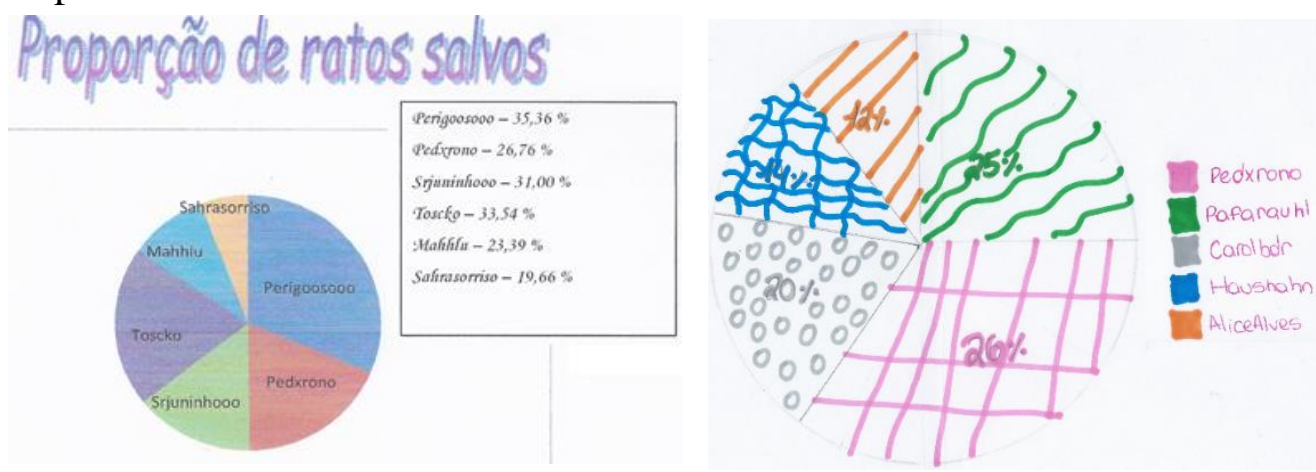

Figura 2: Comparação do desempenho dos jogadores no Transformice.

Fonte: Elaborado pelos alunos.

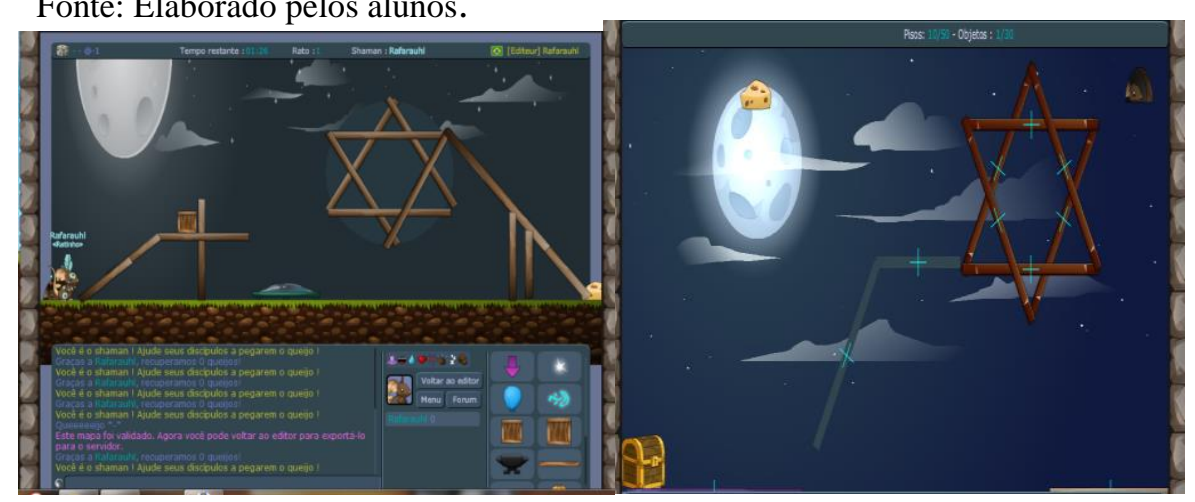

Figura 3: Construção de mapas dos alunos aplicando os conceitos estudados.

Fonte: Elaborado pelos alunos.

Em relação ao eixo Grandezas e Medidas, inicialmente, foi trabalhado o triângulo retângulo identificando seus elementos (catetos e hipotenusa) para a compreensão do Teorema de Pitágoras. Realizaram atividades intuitivas como quebracabeça para compreender o teorema. Além disto, os alunos jogaram Transformice em aula com o objetivo de perceber a aplicação do Teorema de Pitágoras no game. Resolveram exercícios propostos no livro didático visando aplicar o Teorema em função do jogo. Atividades propondo a criação de estratégias no jogo para a tomada de decisão bem sucedida, refletindo e analisando estratégias de outros jogadores verificando se as decisões tomadas auxiliam o maior número de ratinhos no menor tempo possível. Além disto, a estimativa de distância para a construção, enquanto Shamam (líder dos ratinhos na sala), de barras de madeiras para "ligar" os ratos até ao queijo ou a toca, sendo assim, uma maneira intuitiva de aplicar o Teorema de Pitágoras, pois esta distância é a medida da hipotenusa. 
Ao jogar Transformice em aula os alunos manifestaram empolgação, entusiasmo e disposição para jogar e partilhar com a turma suas descobertas, percepções e relações entre o jogo e os conteúdos trabalhados em aula, ou seja, a teoria relacionada e aplicada com a prática. Além disto, durante as aulas de Matemática, no laboratório de informática para jogar, percebeu-se uma integração entre os alunos, até então inexistente, jogavam na mesma sala, assim um conversa com o outro por meio do chat e oralmente. As conversas tinham o objetivo de auxiliar algum colega, um ajudava o outro para jogar melhor ou conseguir concluir um mapa.

Finalizando com o Aluno 17,

\begin{abstract}
“A Matemática não precisa de nenhum jogo para ensinar um conteúdo... claro que fica bem melhor, mas a Matemática ajudou a gente de pensar mais rápido e se dar melhor no jogo. Claro que quando a gente tiver jogando ninguém vai parar pra calcular o teorema, mas com a experiência a gente vê que a barra (refere-se a hipotenusa) sempre vai ser maior que os outros dois e que se a gente fizer reto vai mais rápido... o olho da gente ficou melhor. [...] ah! E também quando a gente constrói os mapas usa muito a Matemática.",
\end{abstract}

O envolvimento e o comprometimento dos alunos ficaram evidentes durante a aplicação do projeto refletindo nas falas dos mesmos. Outra evidência importante é a internalização dos conceitos estudados durante este período, pois conseguiram relacionar e aplicar nos exercícios e no seu dia-a-dia, influenciando diretamente na sua percepção da disciplina, desmistificando-a, e no seu desempenho enquanto jogadores, pois desenvolveram o raciocínio lógico e a estimativa de maneira rápida, o que é fundamental no jogo.

Ao final do desenvolvimento da proposta do estudo de conceitos de Matemática utilizando o Transformice, os estudantes responderam ao questionário final, 17 dos 21 alunos afirmaram ter gostado de utilizar o Transformice para estudar Matemática. Já 4 alunos, que representam 19\% da turma, não gostaram da proposta. Os alunos foram questionados se o uso do Transformice nas aulas de Matemática ajudou-os, ou não influenciou - neutro, ou ainda, atrapalhou no entendimento dos conteúdos abordados. Destacaram-se positivamente os conceitos de Teorema de Pitágoras, hipotenusa, ângulo reto, estimativa de distância, retas paralelas e perpendiculares, entre outros. Entretanto, o estudo de gráfico de setores por meio do Transformice atrapalhou o entendimento dos alunos. Além disto, foi neutro para o entendimento de $\operatorname{arcos}$ e medidas de uma circunferência.

Ao final, 16, do total de 21 estudantes representando $76 \%$ afirmaram que os conceitos estudados por meio do Transformice auxiliaram nas tomadas de decisões no jogo refletindo em um desempenho melhor, ou seja, a Matemática ajudou a desenvolver habilidades que fizeram ter um melhor desempenho no jogo.

Quando questionados se gostariam de continuar estudando Matemática por meio de jogos online a resposta foi unânime, ou seja, 100\% dos alunos gostariam de continuar estudando Matemática com jogos online, pois afirmam ser mais divertido e interessante aprender com os jogos.

Finalizando o questionário os alunos expressaram suas conclusões e sugestões. O Aluno 15 relata "Acho que deveríamos continuar jogando e procurando matemática em jogos diversos.", já o Aluno 16 afirma que "gostei de utilizar o jogo nas aulas de Matemática, pois ajudou a entender melhor alguns conteúdos.", outra sugestão do Aluno 12 "Poderíamos jogar mais jogos de acordo o que vamos estudar a seguinte. Estudar o que os alunos tem mais dificuldade de aprender.". "Acho que para o próximo 
jogo poderia ser minecraft, pois é pura Matemática e pode fazer o que quiser! Não está somente limitado a uma sala com pessoas desconhecidas."

\section{Conclusão}

Este artigo abordou que os jogos têm o poder de aproximar e desmistificar a realidade escolar, pois o princípio do estudo é ancorado ao conhecimento prévio que é o jogo estabelecendo relações e associando o mesmo com a Matemática. Aplicaram intuitivamente, quando realizaram a construção dos mapas, a relação entre ângulos suplementares e ângulos opostos pelo vértice. Neste sentido, ao aplicar e externar os conceitos que utilizam intuitivamente são consequências da reflexão para compreender e associar a teoria do conteúdo curricular e a prática no jogo. Ou seja, perceberam a Matemática aplicada diretamente ou intuitivamente nos jogos, isto é, na vida dos discentes. Neste sentido, o jogo enquanto conhecimento prévio que o aluno possui e, ao mesmo tempo, como ponte cognitiva o auxiliou na compreensão (categoria a priori) de conceitos de Matemática.

Cox (2008) afirma que quando a educação é abordada sob o ponto de vista tecnológico, neste caso, por meio do uso de games, a relação entre professor e aluno se difere, pois o estudante e o professor são companheiros de aprendizagem e o que faz ambos aprenderem são as experiências, as trocas e as reflexões que ocorrem durante o processo. A colaboração, última categoria enunciada, assim como a interação ficaram evidentes durante todo o experimento. Refere-se aqui a interação e colaboração de alunos e alunos, assim como de professora e alunos. Isto, pois, com perspectiva dinâmica e envolvente que o jogo proporcionou nas aulas aumentou a interação entre os alunos, bem como o respeito e as "trocas" entre eles.

Por fim, a proatividade e a autonomia desenvolvidas e reveladas mediante as interações entre conteúdo e aplicação com o Transformice, tendo em vista que com uma perspectiva diferenciada de ensino os estudantes demonstraram confiança, neste sentido tomavam iniciativas sem medo de errar, arriscaram-se e, por consequência, tornaram-se autônomos e proativos. Além de perceberem que ao ter consciência do conhecimento matemático que aplicam ao jogar melhorava o desempenho dos alunos no jogo.

\section{Referências Bibliográficas}

BEHRENS, M. A. O paradigma emergente e a prática pedagógica. RJ: Vozes, 2005. COX, K. K. Informática na Educação Escolar: polêmicas do nosso tempo. Campinas, SP: Autores Associados, 2008.

MATTAR, J. Games em Educação: como os nativos digitais aprendem. São Paulo: Pearson Prentice Hall, 2010.

MORAES, R.; GALIAZZI, M. C. Análise textual discursiva. Ijuí: Unijuí, 2011. MOREIRA, M. A. Mapas Conceituais e Aprendizagem Significativa. Porto Alegre: UFRGS, 2003.

PRENSKY, M. Digital Natives, Digital Immigrants. MCB University Press, Vol. 9, No. 5, October 2001.

"Don't bother me mom - I'm learning!": how computer and video games are preparing your kids for 21st century success. SP: Phorte, 2010.

SÁNCHEZ HUETE, J. C.; FERNÁNDEZ BRAVO, J. A. O ensino da Matemática: fundamentos teóricos e bases psicopedagógicas. Porto Alegre: Artmed, 2009.

VEEN, W.; VRAKKING, B. Homo Zappiens: educando na era digital. Porto Alegre: Artmed, 2009.

ZABALZA, M. A. Diários de aula: um instrumento de pesquisa e desenvolvimento profissional. Porto Alegre: Artmed, 2004. 